\title{
POLÍTICAS DE FORMAÇÃO DE LEITORES NO FINAL DA DÉCADA DE 1960: NANCY LARRICK (1969) E AS ORIENTAÇÕES PARA PAIS E PROFESSORES
}

\author{
Policies for training readers at the end of the 1960s: Nancy Larrick (1969) and \\ guidelines for parents and teachers
}

\author{
Políticas para la formación de lectores a finales de los años 60: Nancy Larrick (1969) y \\ directrices para padres y profesores
}

\author{
Franciele Ruiz Pasquim* \\ Vivianny Bessão de Assis*
}

\begin{abstract}
Resumo
Com o objetivo de contribuir para a compreensão da história da formação de professores e para a história da literatura infantil brasileira, analisou-se a configuração textual do Guia dos pais na escolha de livros para crianças, de Nancy Larrick, especialista nos assuntos relacionados à leitura para crianças, publicado pelo Centro de Bibliotecnia para o Desenvolvimento do Instituto "Roberto Simonsen" (SP), em 1969. Esse livro é a tradução do original norte-americano A parent's guide to childreen's reading, publicado pelo Franklin Book Programs, em 1958. A tradução em língua portuguesa foi feita pela professora Alcina Jorge de Almeida e a adaptação pelo jornalista Leonardo Arroyo, com a supervisão do professor e psicólogo Manoel Lourenço Bergström Filho. Os resultados obtidos por meio da análise do Guia dos pais ... têm contribuído para a compreensão da necessidade apontada por especialistas em literatura infantil, leitura e bibliotecas para a infância, em meados do século XX, dentre eles Leonardo Arroyo e Lenyra Fraccaroli, quanto à orientação de pais e professores na escolha de bons livros para crianças e jovens. Nesse contexto educacional brasileiro, destaca-se também a elaboração de catálogos de livros para crianças, uma prática iniciada pelos pioneiros Lenyra Fraccaroli e Leonardo Arroyo.
\end{abstract}

PALAVRAS CHAVE: Leitura; Livros para crianças; História da Literatura Infantil

\begin{abstract}
In order to contribute to the understanding of the history of teacher education and the history of Brazilian children's literature, the textual configuration of the Parents' Guide in the choice of children's books, by Nancy Larrick, an expert in matters related to reading, was analyzed for children, published by the Center for Librarianship for Development of the Institute "Roberto Simonsen" (SP), in 1969. This book is the translation of the North American original A parent's guide to childreen's reading, published by Franklin Book Programs, in 1958. The translation into Portuguese was done by professor Alcina Jorge de Almeida and the adaptation by journalist Leonardo Arroyo, under the supervision of professor and psychologist Manoel Lourenço Bergström Filho. The results obtained through the analysis of the Parents' Guide ... have contributed to the understanding of the need pointed out by specialists in children's literature, reading and libraries for childhood, in the mid-20th century, among them Leonardo Arroyo and Lenyra Fraccaroli, regarding guidance from parents and teachers in choosing good books for children and young people. In this Brazilian educational context, the creation of children's book catalogs also stands out, a practice initiated by pioneers Lenyra Fraccaroli and Leonardo Arroyo.

\footnotetext{
${ }^{*}$ Doutora em Educação. Universidade Estadual Paulista (UNESP/Marília). Professora da Faculdades FACCAT, Tupã-SP. E-mail: francielepasquim@gmail.com.

* Doutora em Educação. Universidade Federal de Mato Grosso do Sul (UFMS/Naviraí). Professora Ajunta, Campus de Naviraí-MS. E-mail: viviannybessao@gmail.com.
} 
KEYWORDS: Reading. Books for children. History of Children's Literature.

\section{Resumen}

Con el fin de contribuir a la comprensión de la historia de la formación del profesorado y la historia de la literatura infantil brasileña, se analizó la configuración textual de la Guía para padres en la elección de libros infantiles, por Nancy Larrick, experta en temas relacionados con la lectura. para niños, publicado por el Centro de Biblioteconomía para el Desarrollo del Instituto "Roberto Simonsen" (SP), en 1969. Este libro es la traducción del original norteamericano Una guía para padres sobre la lectura de childreen, publicada por Franklin Book Programs, en 1958. La traducción al portugués fue realizada por el profesor Alcina Jorge de Almeida y la adaptación por el periodista Leonardo Arroyo, bajo la supervisión del profesor y psicólogo Manoel Lourenço Bergström Filho. Los resultados obtenidos a través del análisis de la Guía para Padres ... han contribuido a la comprensión de la necesidad señalada por especialistas en literatura infantil, lectura y bibliotecas para la infancia, a mediados del siglo XX, entre ellos Leonardo Arroyo y Lenyra Fraccaroli, con respecto a orientación de padres y maestros para elegir buenos libros para niños y jóvenes. En este contexto educativo brasileño, también destaca la creación de catálogos de libros infantiles, una práctica iniciada por los pioneros Lenyra Fraccaroli y Leonardo Arroyo.

PALABRAS CLAVE: Lectura. Libros para niños. Historia de la literatura infantil.

\section{INTRODUÇÃO}

No Brasil, entre as décadas de 1950 e 1960, de acordo com Perroti (1990), houve o aperfeiçoamento dos "[...] processos de produção, circulação e consumo do livro infantojuvenil" (PERROTI, 1990, p.14). Os maiores consumidores dessa produção ainda continuavam sendo os professores, por utilizarem o livro infantil "[...] com finalidade de ensinar às nossas crianças, de maneira mais agradável, valores morais e sociais, assim como padrões de conduta [...]" (MORTATTI, 2001, p.12).

Essa preocupação inicial esteve mais diretamente relacionada às necessidades educacionais da escola e às inúmeras tentativas de tornar a leitura um hábito e de popularizar os livros para o maior número de pessoas. Dentre essas inciativas para reverter o analfabetismo, destacam-se "[...] campanhas de distribuição de livros, congressos, seminários internacionais, regionais e locais, publicações especializadas, feiras de livros, cursos de formação, criação de entidades, associações, enfim, um conjunto de ações [...]” (PERROTI, 1990, p. 13).

Concomitantemente a essas tentativas, foram criadas entre as décadas de 1960 e 1970, importantes instituições voltadas para o estudo, a promoção, a divulgação e a normatização da leitura e da literatura para crianças, destacam-se dentre elas: a Fundação do Livro Escolar, criada em 1966; a Fundação Nacional do Livro Infantil e Juvenil (FNLIJ), criada em 1968; o Centro de Estudos de Literatura Infantil e Juvenil (CELIJ), criado em 1973; e a Academia Brasileira de Literatura Infantil e Juvenil (ABLIJ), criada em 1979 (LAJOLO; ZILBERMAN, 1984).

Fora dos limites escolares, os livros destinados às crianças passaram a circular também nas bibliotecas infantis e bibliotecas escolares, o que contribuiu para a inauguração de um novo circuito desse gênero literário no Brasil. Esses livros passaram a ser avaliados por professores, bibliotecários e demais autoridades de ensino, não apenas pela sua 
intencionalidade educativa, mas, sobretudo, pela sua contribuição para formar o hábito e despertar o gosto pela leitura nas crianças.

Em meio às possibilidades de leitura disponíveis no mercado editorial, ainda em processo de consolidação, era urgente distinguir os livros mais adequados para as crianças e para a realização dessa difícil tarefa, professores, bibliotecários e demais estudiosos da literatura infantil eram recorrentemente consultados quanto à indicação e à orientação de leituras para as crianças. Dentre esses estudiosos da literatura infantil, destacam-se: o jornalista Leonardo Arroyo (1918-1985) ${ }^{1}$ e a bibliotecária Lenyra Camargo Fraccaroli (1908$1991)^{2}$, por terem se tornado especialistas nos assuntos relacionados à literatura infantil.

Dentre as publicações especializadas, destaca-se o livro Guia dos pais na escolha de livros para crianças (1969), tradução e adaptação do original norte-americano A parent's guide to childreen's reading (1958), de Nancy Larrick. A adaptação desse livro para a realidade brasileira foi feita por Leonardo Arroyo, com a supervisão de Manuel Bergström Lourenço Filho, especialistas em literatura infantil, leitura e bibliotecas quanto à orientação de pais e professores na escolha de bons livros para crianças e jovens a partir da década de 1960 .

Neste texto, portanto, apresenta-se a análise da configuração textual ${ }^{3}$ desse livro com os objetivos de contribuir para a compreensão sobre a história da formação de professores no Brasil, bem como sobre a história da literatura infantil, destinados a pais e professores na década de 1960. Os resultados obtidos por meio da análise desse livro permitem compreender que as adaptações feitas por Leonardo Arroyo, com a supervisão de Manuel Bergström Lourenço Filho, estão relacionadas aos estudos da psicologia no debate educacional desse período.

\section{Lenyra Fraccaroli, Leonardo Arroyo e Nancy Larrick: contribuições dos especialistas de e para a literatura infantil brasileira}

Conforme mencionado, dentre os estudiosos da literatura infantil brasileira, destacamse: o jornalista Leonardo Arroyo (1918-1985) e a bibliotecária Lenyra Camargo Fraccaroli (1908-1991), por atuarem profissionalmente em prol dos livros, das crianças e das bibliotecas e por terem sido considerados especialistas nos assuntos relacionados à literatura infantil a partir da década de 1960.

Lenyra Camargo Fraccaroli diplomou-se no curso de formação de professores da Escola Normal de São Paulo, em 1932, tendo desempenhado a função de bibliotecária e inspetora nessa instituição. Em 1936, dirigiu a Biblioteca Municipal Infantil de São Paulo-

\footnotetext{
1 Sobre a produção de e sobre literatura infantil de Leonardo Arroyo ver, especialmente, a tese de doutorado de Vivianny Bessão de Assis intitulada A contribuição de Leonardo Arroyo (1918-1985) para a história da literatura infantil brasileira (ASSIS, 2016), defendida em 2016, sob a orientação da Prof ${ }^{\mathrm{a}}$. Dr ${ }^{\mathrm{a}}$. Maria do Rosário Longo Mortatti, no âmbito do GPHELLB.

2 Sobre a contribuição de Lenyra Camargo Fraccaroli para a história da literatura infantil brasileira ver, especialmente, a tese de doutorado intitulada Lenyra Camargo Fraccaroli (1908-1991) na história da literatura infantil brasileira: contribuições de uma bibliotecária educadora (PASQUIM, 2017), defendida em 2017, sob a orientação da Prof ${ }^{\mathrm{a}}$. Dr ${ }^{\mathrm{a}}$. Maria do Rosário Longo Mortatti, no âmbito do GPHELLB.

${ }^{3} \mathrm{O}$ método de análise da configuração textual contribuiu para a compreensão do "[...] conjunto de aspectos constitutivos de determinado texto, os quais se referem: às opções temático-conteudísticas (o quê?) e estruturaisformais (como?), projetadas por um determinado sujeito (quem?), que se apresenta como autor de um discurso produzido de determinado ponto de vista e lugar social (de onde?) e momento histórico (quando?), movido por certas necessidades (por quê?) e propósitos (para quê), visando a determinado efeito em determinado tipo de leitor (para quem?) e logrando determinado tipo de circulação, utilização e repercussão" (MORTATTI, 2000 , p. $31)$.
} 
capital $^{4}$, devido a sua experiência como bibliotecária. Em 1940, formou-se em Biblioteconomia, pelo curso de Biblioteconomia da Escola de Sociologia e Política de São Paulo, na cidade de São Paulo-capital. Em 1950, tornou-se chefe da Divisão de Bibliotecas Infanto-Juvenis do estado de São Paulo, o que possibilitou a ampliação do campo de suas ações em prol do livro, da leitura e do leitor. Em 1953, teve publicado o catálogo Bibliografia de literatura infantil em língua portuguêsa $(1953)^{5}$. Em 1961, após sua aposentadoria, embora afastada da direção da biblioteca, continuou envolvida com as questões relacionadas à literatura infantil, tendo-se tornado, em 1978, Presidente de Honra da Academia Brasileira de Literatura Infantil e Juvenil (ABLIJ), de que foi fundadora (PASQUIM, 2017).

A atuação de Fraccaroli como bibliotecária na Escola Normal e na Biblioteca Infantil Municipal contribuiu para a sistematização de um conjunto de práticas pioneiras quanto à organização e ao funcionamento de bibliotecas infantis e que se tornaram modelares no estado de São Paulo e em outros estados brasileiros. O catálogo Bibliografia de literatura infantil em língua portuguêsa (1953) ${ }^{6}$, elaborado por Fraccaroli, contribuiu diretamente para a constituição de acervos de bibliotecas infantis e indiretamente para impulsionar a produção do mercado editorial de livros de literatura infantil e juvenil brasileira, tornando-se obra de referência para professores e catalogadores das bibliotecas infantis e escolares, na seleção de livros de literatura infantil.

A versão brasileira do Guia dos pais na escolha de livros para crianças, de Nancy Larrick (1969), foi publicada mais de uma década depois do catálogo de Lenyra Fraccaroli., publicado em 1953. O livro de Larrick retoma a iniciativa de Lenyra Fraccaroli, conforme destacou Arroyo (1969) em seu texto de apresentação: "O volume completa o esfôrço pioneiro de Lenyra C. Fraccaroli na bibliografia de livros para a infância" (ARROYO apud LARRICK, 1969, p.7).

Leonardo Arroyo foi convidado para fazer a adaptação e apresentação desse livro em decorrência de sua longa trajetória de estudos e publicações na área da literatura para crianças, iniciada em 1946, com a adaptação de contos clássicos da literatura infantil universal para a coleção "Encantada" da Editora LEP (SP). Desde então, envolveu-se intensamente com essa área tendo publicado quatro livros de literatura infantil e juvenil, um deles, intitulado Histórias do Galo e do Candimba (1961), indicado em Guias de pais... na categoria de "livros de ação rápida", para crianças que já leem sozinha (ASSIS, 2016).

Concomitantemente a sua atuação como jornalista, Arroyo foi um pesquisador da história da literatura infantil brasileira, tendo publicado os resultados de suas pesquisas em 60 artigos de jornais, nove capítulos de livro e no livro mais conhecido de sua produção, intitulado Literatura infantil brasileira: ensaio de preliminares para a sua história e suas fontes, publicado em 1968, um ano antes de Guias dos pais... (1969).

Com esse livro, Arroyo (1968) avança em relação ao que vinha sendo produzido até a década de 1960, no Brasil, em relação aos estudos sobre a literatura para crianças,

\footnotetext{
${ }^{4}$ Sobre a atuação de Lenyra Fraccaroli nessa biblioteca, ver, especialmente, Andreotti (2004).

${ }^{5}$ Por se tratar de pesquisa histórica, nesta e nas demais citações e títulos de livros manteremos a ortografia de época.

${ }^{6}$ Esse catálogo contém 1.843 referências de livros de literatura infantil publicadas no Brasil e em Portugal, entre os anos de 1945 e 1950. Trata-se de uma edição revisada e complementada da "Bibliografia Infantil de Obras Brasileiras", da mesma autora, publicada, em 1945, na revista Literatura e Arte, do Departamento de Cultura do Estado de São Paulo. Abaixo de cada uma das referências de livros apresentadas esse catálogo, há um pequeno comentário, de no máximo três linhas, sobre o enredo do livro e a indicação da idade da criança a quem o livro se destinava. Ao final do catálogo, consta uma relação, por ordem alfabética, de títulos dos livros nele referenciados. (PASQUIM, 2017).
} 
principalmente quanto à organização e sistematização da literatura infantil brasileira, principiada por Lourenço Filho (1943) ${ }^{7}$. De modo geral, em Literatura infantil brasileira, Arroyo (1968) empenhou grande esforço em reunir nomes de escritores, professores e intelectuais que publicaram os primeiros livros nacionais para crianças, destacando as coleções infantis e o papel das editoras na formulação de projetos que visavam "popularizar" o livro infantil. Nesse sentido, a contribuição de Arroyo para a publicação de Guia dos pais ... (1969), foi fundamental para realizar a adaptação desse livro que foi feita com base nos seus conhecimentos sobre o mercado de literatura infantil e juvenil e o que existia no país até aquele momento.

\section{A criança e o livro: orientações de Nancy Larrick sobre leitura}

Nancy Larrick (1910-2004) ${ }^{8}$ foi editora e autora de diversos livros relacionados à promoção da leitura para crianças. Em 1956, fundou a International Reading Association ${ }^{9}$ (IRA), sediada em Newark nos Estados Unidos da América do Norte, com objetivo de promover ações em prol da leitura.

No Brasil, a tradução desse livro foi feita pela professora Alcina Jorge de Almeida ${ }^{10}$, publicado pelo Centro de Bibliotecnia para o Desenvolvimento do Instituto "Roberto Simonsen" 11 (SP), em 1969. A adaptação desse livro foi feita pelo historiador, escritor e jornalista Leonardo Arroyo, que se dedicou, principalmente, à indicação de livros escritos por autores brasileiros e/ou livros adaptados para a língua portuguesa disponíveis no mercado editorial nacional, em substituição aos livros originalmente indicados por Nancy Larrick, em língua inglesa. O livro contém duas apresentações feitas, respectivamente, por Maria Braz, membro do Conselho de Bibliotecnia para o Desenvolvimento do Instituto "Roberto Simonsen" e por Leonardo Arroyo.

A apresentação de Maria Braz centra-se na importância do livro para desenvolver " [...] o hábito de ler, mas para tornar a leitura atraente, proveitosa e relacionada com a vida diária" (BRAZ apud LARRICK, 1969, p.5). Ela destaca as contribuições das adaptações feitas por Leonardo Arroyo a fim de atender às possíveis expectativas dos pais das crianças brasileiras.

$\mathrm{Na}$ apresentação intitulada "Matéria Viva", Arroyo (1969) afirma que o livro de Nancy Larrick, por ser "[...] um verdadeiro manancial de ensinamentos sôbre as relações da criança com o livro. Não possuímos obra congênere em português, embora já tenhamos

\footnotetext{
${ }^{7}$ Em 1943, Lourenço Filho teve publicado o artigo "Como aperfeiçoar a Literatura Infantil" na Revista Brasileira, a pedido do então Presidente da Academia Brasileira de Letras, Embaixador José Carlos de Macedo Soares. Nesse artigo Lourenço Filho (1943) apresenta uma análise de aspectos que envolviam a criação, produção, circulação e crítica da literatura infantil no Brasil, até aquele momento histórico. A partir disso, o autor apresenta sugestões para o aperfeiçoamento da literatura infantil, tais como medidas de esclarecimento social sobre o assunto, estímulos a autores nacionais e critérios de aferição dos livros infantis. Sobre a análise da produção sobre e de literatura infantil de Lourenço Filho, ver especialmente, Bertoletti (2012).

${ }^{8}$ Mais informações biográficas de Nancy Larrick, disponíveis em: http://biography.jrank.org/pages/1210/LarrickNancy-1910-2004.html. Acesso em; 22 mar.2017.

${ }^{9}$ Em 2015, a International Reading Association (IRA) alterou o nome para Internacional Literacy Association (ILA), com o objetivo de ampliar seu campo de atuação, atualmente, especializado na alfabetização de crianças. Dentre a ações dessa associação, destacam-se o desenvolvimento de projetos globais sobre alfabetização e a publicações de revistas e livros, resultantes de pesquisa sobre tema. Para mais informações, acesse o site: http://biography.jrank.org/pages/1210/Larrick-Nancy-1910-2004.html. Acesso em: 22 mar. 2017.

${ }^{10}$ Até o momento não localizamos informações sobre Alcina Jorge de Almeida.

${ }^{11} \mathrm{O}$ Instituto Robert Simonsen esteve relacionado às ações para a industrialização do país. O patrono desse instituto, Robert Simonsen, era engenheiro, administrador, historiador e político. Também, foi membro da Academia Brasileira de Letras. Essas informações estão disponíveis em: http://www.fiesp.com.br/institutoroberto-simonsen-irs/sobre-roberto-simonsen. Acesso em: 23 mar. 2017.
} 
especialistas capazes de fazê-la no âmbito da temática [...]" (ARROYO apud LARRICK, 1960, p.7).

Dentre os especialistas da literatura infantil por ele mencionado, destacam-se as contribuições de Lourenço Filho ${ }^{12}$ e Cecília Meireles ${ }^{13}$ quanto aos estudos pioneiros sobre o tema na década de 1940 e a importância de Lenyra Fraccaroli quanto à publicação de uma bibliografia específica para as crianças brasileiras na década de 1950.

Segundo Arroyo (1969), apesar das diferenças culturais claramente existentes entre a cultura norte-americana e a brasileira, é possível observar nesse Guia, "lições de validade universal" no que se refere ao desenvolvimento do hábito da leitura nas crianças.

Figura 1: LARRICK, Nancy. Capa do livro Guia dos pais na escolha de livros para crianças, 1969.

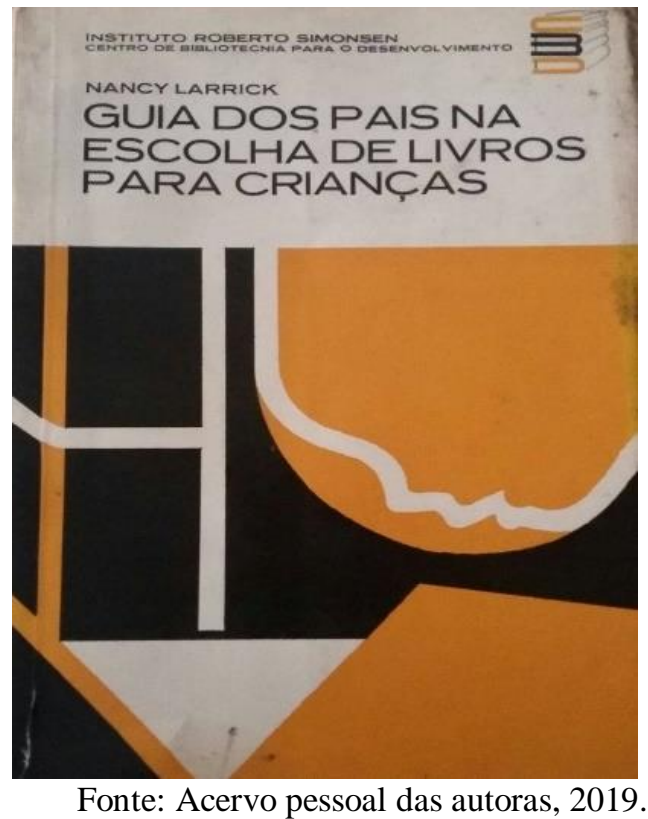

Na primeira parte, Larrick (1969) ressalta a importância da leitura em voz alta, por ser uma das "[...] poucas atividades [que] podem criar uma relação mais terna entre uma criança e um adulto" (LARRICK, 1969, p. 20). De modo geral, a autora organiza a indicação dos livros de acordo com a idade das crianças: livros para crianças com menos de quatro anos, livros para crianças de cinco a sete anos e livros para crianças de nove a 12 anos. Na iniciação da leitura, os textos mais indicados são os versos infantis ou as músicas com versos repetidos, além dos livros sobre animais, por serem os temas mais atraentes para as crianças menores.

É importante ressaltar a ênfase dada pela autora ao orientar os pais para que adquiram livros sobre os temas que mais interessam as crianças, o que indica a ruptura com o modelo tradicional de educação. Os livros a serem lidos para elas deveriam ser escolhidos conforme os interesses individuais das crianças, caso contrário estaríamos "[...] usando um método de carro de bois na era do jato" (LARRICK, 1069, p.125).

A autora apresenta um "roteiro" de como os pais podem ajudar os filhos na "fase inicial" de aprendizado da leitura e da escrita. São sete, os passos a serem dados pelos pais:

\footnotetext{
${ }^{12}$ Ver nota 7.

${ }^{13}$ De sua autoria, ver, especialmente, as três conferências proferidas pela poetisa Cecília Meireles na cidade de Belo Horizonte (MG), posteriormente, publicadas no livro Problemas da literatura infantil, em 1951.
} 
[...] 1) mostre à criança que podemos confiar nela [...] 2) Mostre interesse pela vida escolar 3) Cuide das boas condições físicas da criança [...] 4) Ajude-a conhecer outras crianças [...]5) Acostume-se a falar com clareza [...] 6) Utilize jogos de palavras [...] 7) Responda a perguntas que a criança faça [...] (LARRICK, 1969, p. 38 , grifos da autora).

O mais importante, para Larrick (1969), é os pais mostrarem “[...] à criança que a leitura diverte." (p. 38). Para as crianças em fase escolar, os livros mais indicados são os relacionados a trens, navios, aviões, foguetes, animais pré-históricos, insetos, e a vida. A autora incentiva os pais a participarem da vida escolar dos filhos, buscando compreender como é ensinada a leitura na escola. Os pais devem ler histórias em voz alta para que, posteriormente, as crianças possam realizar a leitura sozinha. Para que as crianças leiam cada vez mais e melhor, os pais também devem oferecer a maior variedade de livros para as crianças, de acordo com seus interesses particulares (LARRICK, 1969, p. 44).

Orienta ainda acerca das características que o livro precisa ter para atender às crianças na fase inicial da leitura. Devem-se observar os seguintes aspectos:

[...] tipo é grande e claro; [...] vocabulário é simples e as sentenças são curtas (muitas vêzes quatro ou cinco palavras apenas); [...] com interrupções nas pausas naturais da conversação; [...] poucas linhas em cada página [e] gravuras dão sugestões que facilitam a leitura. (LARRICK, 1969, p. 47).

De acordo com a autora, na fase entre os nove e 12 anos de idade, as crianças começam a interessar-se por outros assuntos, como esportes, amigos, viagens, construções e coleções e novos passatempos. Para fase em que as crianças já leem sozinhas, a autora indica livros de ação rápida e de aventuras envolvendo índios e animais selvagens, viagens que relatam lugares desconhecidos, histórias de ficção científica e viagens a outros planetas.

As orientações de Larrick (1969) sobre os livros mais indicados de acordo com a idade das crianças são seguidas de diversas indicações de livros disponíveis no mercado brasileiro, presumivelmente, feitas pelo adaptador Leonardo Arroyo. As adaptações feitas por Arroyo à realidade do mercado e da cultura nacional tornaram o livro de Larrick mais interessante, pela identidade brasileira que ele imprimiu ao livro.

Larrick (1969) dedica-se ainda a dois temas polêmicos, apontados também por especialistas brasileiros, que se referem às histórias em quadrinhos e à televisão. Embora afirme que as histórias em quadrinhos sejam apreciadas, principalmente, pelos leitores jovens, a autora desaconselha esse tipo de leitura, por trazerem em seus enredos "[...] assassinatos misteriosos, violência e mesmo motivos eróticos." (p. 76).

Para combater as histórias em quadrinhos, há a indicação de livros que poderiam substituí-las e, de modo geral, esses livros precisavam ser mais curtos e bastante ilustrados. A indicação dos livros foi classificada pelos seguintes temas: "Histórias engraçadas de animais"; "Aventuras de crianças"; e "Histórias de aventura e emoção" (LARRICK, 1969).

Larrick (1969) também adverte os pais sobre o tempo em que os filhos passam assistindo televisão, não sobrando tempo suficiente para que se dediquem a leitura. No entanto, a autora destaca que a televisão pode "[...] dar motivação à leitura [...]" (p. 84). Nesse sentido, a televisão aparece com uma conotação mais positiva em relação às histórias em quadrinhos, podendo ser uma "ponte" para a leitura.

Larrick (1969) conclui a primeira parte explicitando a necessidade de se ter em casa livros de consulta, como dicionários, almanaques, atlas e enciclopédias. Esses livros são importantes para as crianças em fase escolar, por contribuírem para o desenvolvimento de 
outras técnicas de leitura, tendo em vista a finalidade de cada um desses livros. Arroyo indica as mais novas edições ilustradas destinadas aos jovens brasileiros.

Na segunda parte do livro, "Como a leitura é agora ensinada", Larrick (1969) destaca que as crianças deveriam "[...] ser preparadas para ler entendendo" $(1969$, p.110, grifos da autora). Os bons leitores seriam aqueles que falam bem e que compreendem o que leram. Para compreender o que se leu, seria necessário que os pais e professores ensinassem às crianças "[...] diferentes técnicas para decifrar as palavras no ato de ler" (LARRICK, 1969, p.111). Desse modo, é preciso ensinar as crianças que, ao ler, por exemplo, um “[...] artigo científico, teremos de refletir sobre cada trecho, tendo talvez de reler alguns deles para compará-los com os demais" (LARRICK, 1969, p.111). É possível perceber que essas técnicas estão diretamente relacionadas à finalidade para a qual um texto é escrito.

O leitor precisará recorrer aos conhecimentos prévios que se relacionem com o assunto do livro que irá ler. Para a formação desse tipo de leitor, a autora propõe que a professora ensine às crianças a "[...] perceber[em] indícios que facilitem cada uma dessas atividades, mediante o uso de palavras parecidas, tenham elas sentido próximo, ou não" (LARRICK, 1969, p.113).

A professora deverá escrever sentenças sobre os trabalhos a serem por elas realizados ao longo do dia escolar, como, por exemplo, "Vamos ler histórias" (LARRICK, 1969, p.114). Para aperfeiçoar a compreensão das crianças sobre o que leram, segundo a autora, as professoras devem

[...] organizar excursões, que permitam que às crianças melhor preparar-se para compreender o assunto de determinados livros. Um passeio a um jardim zoológico [...] enriquecem consideravelmente o espírito do leitor para a compreensão de certas histórias (LARRICK, 1969, p.118).

A repetição da leitura dessas sentenças e a comparação com outras fará com que as crianças desenvolvam a "leitura global" (p.114). Essa fase da leitura poderá ser aperfeiçoada pela elaboração de listas de palavras que comecem com o mesmo som, o que contribuirá para "ensinar fonética" (LARRICK, 1969, p.115). Segundo Larrick (1969), o sucesso na aprendizagem da leitura dependerá das experiências adquiridas pelas crianças durante os primeiros cinco anos de vida. Se manusearem bons livros e ouvirem boas histórias, provavelmente, serão bons leitores, porém é preciso também considerar a "maturidade" de cada criança quanto à aprendizagem da leitura.

A autora cita o livro Testes $A B C$ para a verificação da maturidade necessária à aprendizagem da leitura escrita (1934), de autoria de Lourenço Filho ${ }^{14}$. Segundo ela, a maturidade da criança depende de fatores, tais como: "idade"; "sexo"; "inteligência geral"; "boa saúde"; "capacidade de ver e ouvir bem"; "hábito de ouvir com atenção"; e "linguagem oral"; "confiança em si mesma"; "estabilidade emocional"; e "desejo de ler" (LARRICK, 1969, p.121-122).

Essa verificação será feita pela professora, por meio da aplicação de provas e testes, os quais darão mais exatidão sobre o quão madura ou preparada está uma criança para aprender a ler. Assim, nas escolas, as crianças serão "[...] organizadas [em] várias classes, segundo os níveis próximos de maturidade. Então, cada professor poderá trabalhar mais eficientemente, adaptando os procedimentos que mais convenham a cada grupo". (LARRICK, 1969, p.123)

\footnotetext{
${ }^{14}$ Para informações mais detalhadas sobre a contribuição de Lourenço Filho para a história da alfabetização e história da literatura infantil, ver, respectivamente, as pesquisas pioneiras de: Mortatti (2000); e Bertoletti (2006, 2012).
} 
A escolha dos livros a serem lidos pelas crianças será também decorrente da aplicação dos testes $\mathrm{ABC}$, o que possibilitará o aperfeiçoamento de acordo com as características individuais das crianças. Os testes serão úteis para "[...] medir o progresso da criança na leitura em comparação com o mesmo progresso dos demais alunos de sua classe, para que se descubram os pontos fracos que casa aluno apresente" (LARRICK, 1969, p.125).

Na terceira parte do livro ${ }^{15}$, “A aquisição de livros para crianças", Larrick (1969) destaca a importância da adequação a leitura conforme a idade e o interesse de cada criança. Os livros de figuras e com ilustrações atraentes seriam mais indicados para as crianças menores. A autora destaca a importância das bibliotecas públicas e escolares para as crianças, cujos pais não podem adquirir os livros para a organização de uma biblioteca em seus lares. Ainda a esse respeito, destaca a "[...] necessidade de bibliotecas por tôda parte" (LARRICK, 1969, p.134).

Nessa perspectiva, as bibliotecas seriam como um lar para que as crianças pudessem ser educadas pelas bibliotecárias, que a semelhança das mães, poderiam contribuir para a formação do caráter infantil, oferecendo-lhes bons hábitos, em especial, os relativos ao desenvolvimento do gosto pelas boas leituras, ou seja, aquelas que possibilitariam o bem.

\section{Políticas de leitura para infância: contribuições de Fraccaroli, Larrick e Arroyo}

Conforme apresentado anteriormente, a partir da década de 1960, segundo Mortatti (2011), surgiram no Brasil, diferentes instituições encarregadas de estudar o problema do livro e da leitura no país. A bibliotecária educadora Lenyra Fraccaroli e o jornalista Leonardo Arroyo se tornaram fundamentais nesse processo de promoção e divulgação da leitura, em especial por contribuírem para a legitimação de uma concepção de literatura infantil brasileira pautada nos princípios da psicologia educacional, a qual considerava o interesse e maturidade das crianças para a leitura de determinados livros.

No cenário brasileiro, as políticas propiciaram a ampliação de órgãos já existentes como é o caso do Instituto Nacional do Livro, criado em 1937 e a criação de outras instituições, tais como: a Fundação Nacional do Livro Infantil e Juvenil, criada em 1968, como a seção brasileira do International Board on Books for Young People - IBBY; o Centro de Estudos de Literatura Infantil e Juvenil, criado em 1973, bem como a criação da Academia Brasileira de Literatura Infantil e Juvenil (ABLIJ), de 1979 (LAJOLO; ZILBERMAN, 1984). Juntos, esses espaços reuniam pesquisadores, escritores, bibliotecários e professores interessados em discutir literatura infanto juvenil e sobre a criação de bibliotecas.

Interessante notar que, nesse período as tematizações sobre leitura eram apresentadas por diferentes campos do conhecimento e interfaces, as discussões ocorriam em diferentes setores sociais relacionados com a cultura, a educação e a psicologia. O objetivo principal era formar as crianças leitoras e reverter os altos índices de analfabetismo, talvez um dos focos de todos os envolvidos nessa temática era ver um Brasil cada vez mais como um país de leitores e próximo da realidade de outros países.

É nesse movimento de época que Guia dos pais... de Nancy Larrick ganha força para ser publicado, o que demandou a organização de um trabalho em conjunto, dirigida por Lourenço Filho e efetuada por Leonardo Arroyo. Esse livro, de acordo com Arroyo (1969, p.7), completava "[...] o esforço pioneiro de Lenyra Camargo Fraccarolli na bibliografia [...]" pois, singular em relação ao que estava sendo publicado à época, no Brasil, esse livro

\footnotetext{
${ }^{15}$ Ao final dessa terceira parte, há uma relação das editoras brasileiras que publicam para as crianças, com seus respectivos endereços. Essa relação de nomes de editoras evidencia a importância das adaptações no livro de Larrick feitas por Leonardo Arroyo, exímio especialista da literatura infantil brasileira.
} 
orientava não somente a professores e bibliotecários, mas também a um novo público - os pais - que passaram a ser incluídos nas discussões acerva da formação do hábito de leitura das crianças e jovens.

Considerando a interlocução com esse público, Arroyo (1969) valoriza a linguagem simples do livro, "[...] acessível a qualquer interessado [...]" (p. 8) e salienta que a adaptação foi necessária, pois “[...] muita coisa do que ela [Nancy Larrick] nos diz [...] não servirá para a situação brasileira" (p. 8)

Não foi, porém, tarefa fácil realizar a adaptação para o caso brasileiro. A cultura norte-americana apresenta algumas peculiaridades e certo avanço na faixa da literatura infantil que não nos permite, por várias e numerosas razões que não vêm a pêlo discutir aqui [...]. É o caso, por exemplo, do interêsse da criança americana pelo progresso tecnológico e a pertinente literatura infantil. O número de livros para crianças existentes a respeito nos Estados Unidos é imenso. [...] O que possuímos nesse setor pertence à área da tradução e, assim mesmo, em nível muito deficiente. (ARROYO, 1969, p. 8).

Entre o final da década de 1960 e início de 1970, as tematizações sobre leitura que eram apresentadas por diferentes campos do conhecimento entendiam que, cada vez mais, a formação do hábito de leitura era uma questão cultural, por isso, muito mais ampla, e não poderia restringir-se aos muros escolares e a função dos professores e bibliotecário na escola, mas envolver também aos pais e o cotidiano dos lares brasileiros.

Dar livros às crianças, como dar êsses livros, como despertar o amor da criança pelo livro, o que a criança deve ler e como deve ler - eis a matéria viva desta pequenina obra de Nancy Larrick em suas lições particularmente endereçadas aos pais de jovens leitores. Temos nestas páginas um verdadeiro instrumento de trabalho, destinado a abrir novas perspectivas nesse vasto e complexo campo de livros para crianças. (ARROYO, 1969, p. 9).

Os pais e a família de forma geral representavam a abertura dessas "novas perspectivas" no complexo campo de livros para crianças. Aspectos esses, que podem ser observados em um artigo intitulado "Plano para a formação do hábito da leitura", que Arroyo teve publicado em 1967 no jornal Folha de S. Paulo, localizamos informações de que a publicação desse livro já estava sendo aguardada desde 1967, visto que, serviria como orientação básica para a execução da campanha organizada pelo Ministério da Educação e Cultura que tinha como objetivo promover "[...] a formação do hábito de leitura entre crianças visando o homem futuro [...]" (FOLHA DE S. PAULO, 1967, p.5).

Essa campanha abrangeu uma série de iniciativas, tais como: a criação de Cursos de Literatura Infantil nas escolas; Campanhas de Formação do Hábito de Leitura através do Centro Brasileiro de Pesquisas Educacionais; Criação de Bibliotecas Infantis em todas as escolas, entre outros. A proposta de constituir bibliotecas em casa apresentada nesse livro, foi utilizada como base para essa campanha e chamada de "Uma biblioteca em cada lar", com a finalidade de "[...] manter o hábito da leitura [e]conhecer a realidade brasileira e responder a pergunta: por que as crianças não lêem? [...]”. (FOLHA DE S. PAULO, 1967, p. 5).

Os temas serão fornecidos pela Pesquisa projetada na idéia de "Uma biblioteca em cada lar", essas campanhas devem ser permanentes objetivando não só criar, mas também manter o hábito da leitura. Quanto às publicações institucionais abrangem elas dois pontos principais: 1. Bibliografia Infantil Brasileira, exemplo de trabalho idêntico feito por Lenyra C. Fraccaroli, com base no levantamento feito pelo Departamento de Biblioteconomia. 2. Guia de leitura para pais e mestres, já traduzido, em vias de ser adaptado às condições brasileiras. (ARROYO, 1967, p. 5).

Conforme explicita esse fragmento do artigo, o Ministério da Educação aguardava a finalização do trabalho de adaptação desse livro à realidade brasileira, que estava sendo 
organizado por Leonardo Arroyo, para então implementar as ações dessa campanha. Nesse contexto, o livro de Nancy Larrick torna-se urgente, a fim de que um discurso internacional pudesse também legitimar os conhecimentos sobre leitura dentro do território nacional, na tentativa de equiparar o Brasil as outras nações leitoras.

\section{CONSIDERAÇÕES FINAIS}

Por meio da análise do livro Guia dos pais na escolha de livros para crianças (1969) foi possível observar que, em decorrência de suas respectivas atuações e publicações, Fraccaroli Larrick e Arroyo contribuíram por determinar o que era ou não literatura infantil no Brasil e para a constituição de acervos de livros para crianças, sobretudo, no final da década de 1960. Nessa década, a leitura assumia papel central no debate educacional brasileiro, em meio a diferentes ações que visavam à popularização da leitura, tornando-a um hábito a ser adquirido tanto na escola quanto nas casas das crianças.

Observa-se também que os discursos em torno da leitura e da literatura infantil eram modulados pelos estudos da Psicologia e da Escola Nova nos Estados Unidos e caudatária da sua popularização e adaptação realizada por Lourenço Filho (1897-1970), no Brasil. As questões em torno da formação do hábito da leitura envolviam sempre discussões sobre o desenvolvimento da "maturidade" da criança, a escolha dos livros por temas que atendessem aos interesses desse desenvolvimento e que, acima de tudo, contribuíssem para o belo e o bem na formação moral de um cidadão comprometido com a escola e com progresso do país.

Os resultados obtidos por meio da análise do Guia dos pais na escolha de livros para crianças (1969) contribuem para a compreensão da necessidade apontada por especialistas em literatura infantil, leitura e bibliotecas para a infância, em meados do século XX, dentre eles, a norte-americana Nancy Larrick e os brasileiros Lenyra Fraccaroli, Leonardo Arroyo e Lourenço Filho quanto à orientação de pais e professores na escolha de bons livros para crianças e jovens, aspecto esse ainda pouco explorado na história da literatura infantil brasileira.

Destaca-se ainda que, a publicação do Guia dos pais..., de Nancy Larrick (1969), por ter sido uma importante tematização sobre a escolha de livros para crianças e por ter inspirado a organização de políticas educacionais para a formação de professores e fomentar campanhas para a formação do hábito de leitura e a criação de bibliotecas infantis nas escolas brasileiras. Por fim, por meio da história da educação e a história da leitura tem sido possível lançar luz sobre o passado e compreender aspectos ainda poucos explorados da infância no Brasil.

\section{REFERÊNCIAS}

ANDREOTTI, Azilde L. O acervo de documentários da Biblioteca Infantil de São Paulo (1936-1960): testemunho de uma época revelando sua diversidade. Acervo, Rio de Janeiro, v.18, n.1-2, jan./dez. 2005, p.161-170.

A formação de uma geração: a educação para a promoção social e o progresso do país no Jornal A voz da Infância da Biblioteca Infantil de São Paulo. Tese (Doutorado em História e Filosofia da Educação) - Faculdade de Educação, UNICAMP, Campinas, 2004.

ARROYO, Leonardo. Literatura infantil brasileira: ensaio de preliminares para sua história e suas fontes. São Paulo: Melhoramentos, 1968. 
Plano para a formação do habito da leitura. Folha de S. Paulo. São Paulo, 15 maio 1967. Seção ilustrada, p.5.

ASSIS, Vivianny Bessão. A contribuição de Leonardo Arroyo (1918-1985) para a história da literatura infantil brasileira. 2016. 525 f. Tese (Doutorado em Educação) - Faculdade de Filosofia e Ciências, Universidade Estadual Paulista, Marília, 2016.

BERTOLETTI, Estela Natalina Mantovani. Lourenço Filho e a alfabetização: um estudo de Cartilha do povo e da cartilha Upa, cavalinho. São Paulo: UNESP, 2006.

Lourenço Filho e a literatura infantil. São Paulo: UNESP, 2012.

BORTOLIN, Sueli. A literatura infantil nas Bibliotecas Monteiro Lobato de São Paulo e Salvador. 233f. 2001. Dissertação (Mestrado em Ciências da Informação) - Faculdade de Filosofia e Ciências, UNESP, Marília-SP.

CRUZ, Gutemberg. Gente da Bahia. Salvador: Editora P\&A, 1998. (Volume 2)

LARRICK, Nancy. Guia dos pais na escolha de livros para crianças. Trad. Alcina Jorge de Almeida. São Paulo: Instituto Roberto Simonsen,1969.

MORTATTI, Maria do Rosário. Os sentidos da alfabetização: São Paulo/1876-1994. 2 remp. São Paulo: UNESP, 2000a. 2001. Leitura crítica da literatura infantil. Itinerários, Araraquara, n. 17/18, p. 179-188,

PASQUIM, Franciele Ruiz. Lenyra Camargo Fraccaroli (1908-1991) na história da literatura infantil brasileira: contribuições de uma bibliotecária educadora. 237f. Tese (Doutorado em Educação) - Faculdade de Filosofia e Ciências, Universidade Estadual Paulista, Marília, 2017.

PERROTI, Edmir. Confinamento cultural, infância e leitura. São Paulo: Summus, 1990.

VÁLIO, Else Benetti Marques. Biblioteca escolar: uma visão histórica. Trans- in-formação 1(1), Campinas, p.15-25, jan./abr. 1990.

ZILBERMAN, Regina; LAJOLO, Marisa. A literatura infantil brasileira entre a teoria (Literária) e a prática (Escolar). In: ZILBERMAN, Regina; LAJOLO, Marisa. Um Brasil para crianças: para conhecer a literatura infantil brasileira. São Paulo: Global, 1987. p.247-257.

Recebido em: 03/05/2019

Aprovado em: 05/07/2019 